Jeff Grupp*

\title{
The Implantation Argument: Simulation Theory is Proof that God Exists
}

https://doi.org/10.1515/mp-2020-0014

published online September 13, 2021

Abstract: I introduce the implantation argument, a new argument for the existence of God. Spatiotemporal extensions believed to exist outside of the mind, composing an external physical reality, cannot be composed of either atomlessness (infinite divisibility, atomless gunk), or of Democritean atoms (extended simples), and therefore the inner experience of an external reality containing spatiotemporal extensions believed to exist outside of the mind does not represent the external reality (inner mind does not represent external, mind-independent, reality), the mind is a mere cinematic-like mindscreen (a mindscreen simulation), implanted into the mind by a creator-God. It will be shown that only a creator-God can be the implanting creator of the mindscreen simulation (the creator of reality), and other simulation theories, such as Bostrom's famous account, that do not involve a creator-God as the mindscreen simulation creator, involve a reification fallacy.

Keywords: God, atoms, simulation theory, atomless gunk, proof for the existence of God, spatiotemporal extension

\section{Introduction}

I will present a new proof for the existence of a creator-God, which I call the implantation argument for the existence of God, or just the implantation argument, which is as follows:

1. Spatiotemporally extended objects believed to exist outside of the mind can only be composed of point-sized (sizeless) invisible philosophical atoms, ${ }^{1}$ the

Former affiliation: Lecturer of Philosophy, University of Michigan - Dearborn, Dearborn, MI, USA

1 This will be shown novelly in this article.

*Corresponding author: Jeff Grupp, Pastor and Lead Chaplain, Van Buren County Jail, $205 \mathrm{~N}$. Kalamazoo St., Paw Paw, MI 49079, USA, E-mail: jeffreygrupp@hotmail.com 
atoms cannot gather into perceivable extended objects, and the spatiotemporally extended objects cannot exist (outside the mind).

2. A human's reality is its total set of mind experiences, which cannot be caused by spatiotemporally extended objects that are believed exist externally (outside the mind), the mind is a nonrepresentational internal cinematic-like screen (a mindscreen simulation of an external reality).

3. The experience of reality (mindscreen) is caused and created (call the cause the creator) by the contents of the mind being injected and implanted into the mind from outside of the mindscreen.

4. The cause of reality does not have an ordinary spatiotemporally extended body (from 1), and the cause of reality is outside of reality: it is non-natural, or supernatural.

5. There is a supernatural creator of reality.

6. Therefore, God exists. ${ }^{2}$

The implantation argument follows from the philosophy of point-atomism: basic building blocks of external reality, philosophical atoms, do not have spatial size (hereafter referred to as "dimensionless" atoms). Dimensionless atoms have been discussed and advocated by many for thousands of years in philosophy, and hundreds of years in science (e.g., the point particles of the standard model of quantum physics), often in either case being referred to as involving the paradoxes of spatiotemporal extension, which appear to have started with Zeno's metrical paradox of extension (extended magnitudes are composed of unextended dimensionless atoms). ${ }^{3}$ But to my knowledge, there is no argumentation, until the implantation argument, that reveals how dimensionless atomism involves a variety of simulation theory (inner experience of the world is mind-dependent, and does not represent an external spatiotemporal reality) that proves God exists. Through the

2 Perhaps a simpler wording of the argument is this: 1. perceived external extensions can only in fact be point-atoms, 2. external reality can only be a mindscreen simulation, 3. reality is mind-implanted by a spiritual (nonspatiotemporal) entity outside of ordinary reality, 4 . $\therefore$ God exists.

3 Some readers may assert that Adolf Grünbaum has already solved Zeno's metrical and measure paradoxes, but this is not ubiquitous, and it has further been argued that Grünbaum's metaphysically-oriented topological "solution" to Zeno's paradox of extension involves ad hoc metaphysical inventions (invisible metaphysical relations amongst the points of a continuum that are alleged to be aspects of mind-independent nature), which, when analyzed in detail, can be shown to reduce to contradiction (see Grupp 2006). This is discussed more below. 
past few thousand years, the paradoxes of spatiotemporal external reality have been widely discussed, wherein many have developed pieces and foreshadowings of the implantation argument, ${ }^{4}$ but to my knowledge the entire argument has not been previously devecoped, where dimensionless atomism involves a proof for the existence of God.

I will show that external spatiotemporal reality cannot exist outside of the screen of the mind, and thus can only be created by a source (hereafter also referred to as the creator, or God) that implants mind contents, where that source, we will see below, can only be a creator-God. To show that the external physical reality believed to exist outside of self can only be of the screen of the mind, I present new arguments against both Democritean atomism, and against the philosophy of atomlessness (atomless gunk, infinite divisibility), which are the only two options there are for describing how the smallest levels of any mereological reality can (purportedly) compose the perceived extended spatiotemporal magnitudes of ordinary empirical experience. Both positions reduce to dimensionless atomism (external magnitudes can only be considered to be sizeless dimensionless atoms with no proper parts), but where dimensionless atomism cannot account for the experience of spatiotemporal extended objects in external physical reality. The implantation argument opens with the thesis that the perceived physical-external reality is only describable in terms of contradiction: the visible and perceivable is composed of the invisible and imperceivable, the extended is composed of the unextended, surfaces are composed of nonsurfaces, and colorfulness is composed of noncolor - where another reason and explanation for the experience of empirical reality is needed other than representationalism. It is interesting to note how science and philosophy appear to agree on these points, where the same general problem that Zeno unveiled, that quantum mico-reality and macro-reality are incompatible, is also found in contemporary science, where if one dissects spatiotemporal extensions to a micro-level, the familiar empirical rules, entities,

4 To give one of many examples that could be given, Zimmerman writes:

Some philosophers, including Pierre Bayle, have advanced an even harsher critique of extended substance: not only are there in fact no extended substances, but there could not be any; the very concept of extended substance harbors contradictions, like the concept of a round square... Only if every attempt to understand extension and contact ended in paradoxes would we have cause to conclude, with [Pierre] Bayle, that extended bodies "can only exist ideally" (Zimmerman 1996, 3-4). 
and properties of spatiotemporal physical external reality dissolve, ${ }^{5}$ where quantum weirdness governs, containing roughly the inverse qualities as empirical macro-reality.

But interestingly, these vast and pervasive paradoxes and problems, encountered from so many angles in both science and philosophy, appear to almost fully dissolve when espousing the thesis that ordinary experience of physical external reality is not caused by the spatiotemporally extended magnitudes that are believed to exist mind-independently (outside of the mind), and when espousing the thesis that the ordinary experience of physical and spatiotemporally extended magnitudes of external reality does not represent a reality that is mindindependent. Alternatively, the thesis that one's conscious contents of one's daily reality are, rather, an internal cinema, a simulation, a virtual reality, placed (implanted) in the mind by some unknown, preternatural source, ${ }^{6}$ would be required. If humans do not obtain experience of external physical reality by observing the external physical reality, then the inner experience of an external physical reality that humans have from moment-to-moment is not a representation

5 Brian Greene, the string theorist writes:

... [R]esearch on aspects of M-theory... has shown that something known as a zero-brane - possibly the most fundamental ingredient of M-theory, an object that behaves somewhat like a point particle at large distances but has drastically different properties at short ones - may give us a glimpse of the spaceless and timeless realm... [W] [Wereas strings show us that conventional notions of space cease to have relevance below the Planck scale, the zero-branes give essentially the same conclusion but also provide a tiny window on the new unconventional framework that takes over. Studies with these branes indicate that ordinary geometry is replaced by something known as noncommutative geometry... In this geometrical framework, the conventional notions of space and of distance between points melt away, leaving us in a vastly different conceptual landscape. (Emphasis added.) (Greene 1999, 379).

6 Some may argue that even God is externally perceived, such as in a beatific vision, where God has a form and shape: "And the Father himself, which hath sent me, hath borne witness of me. Ye have neither heard his voice at any time, nor seen his shape”, John 5:37 (Authorized KJV) (Itals added). But according to 1 Peter 4:7, “... the end of all things is at hand: be ye therefore sober, and watch unto prayer", would apparently indicate that the concept of "things" is a temporary concept that is inferior to what God will reveal in the future (1 John 2:17, 1 John 3:2, Col. 4:2, Rom. 8:18) which apparently is a transcendent reality of post-thingness ("the end of all things..."), for lack of better words. For these reasons, when God is beheld in a beatific vision, if a shape is perceived, then that experience would have to be explained in light of the conclusions of this paper: if God is perceived as having shape external to the person, it will be found below that this experience of God-beyond-thingness would need to be describable in some other framework, as an internal God ("if any man be in Christ, he is a new creature", 2 Cor. 5:17), seemingly in some unknown or ineffable way of interaction, and not a creator-God viewed via representationalism. 
of something outside of the inner mind, and rather, such experience is some sort of nonrepresenting internal cinema, or mindscreen, ${ }^{7}$ that is implanted into the mind by some cause. Hereafter I will refer to all human experience and experiencing by terms such as these: mindscreen, mindscreen experience, mindscreen reality, or reality - denoting that ordinary human experiencing in daily life is a mind-dependent (exists only in the mind) cinematic experience (an internal "feeling-cinema", for lack of better words), that cannot be known to represent anything outside of itself. It is this adherence to nonrepresentationalism that makes the simulation theory theology of this paper different than the previous simulation theories (such as Bostrom's (2003) famous account), which invariably rely on representationalism (inner mind contents represent, map, indicate what is outside of mind), therefore involving the thesis that what cannot be represented is represented (contradiction).

Most of moment-to-moment human awareness is composed of internal experience that is felt and believed to about an external physical reality (to be representing an externality), but it will be shown that all such experience is only of the mind (only internal, or mind-dependent), not caused by the perceived spatiotemporal physical externality. Therefore, mindscreen experiencing (reality), is only internal, is implanted into the mind by a source that has the capacity to create a mindscreen reality, and whatever the cause is that is responsible for the creation of mindscreen reality, that cause is, ipso facto, the creator of the human mind and reality. But what sort of entity could have the capacity to cause and create the mindscreen reality, to implant such contents inside of the human mindscreen? If there is an entity that creates the mindscreen, that entity would appear best defined as the creator-God, since mindscreen experience of reality, a nonrepresentational internal cinema, exists because conscious contents are apparently being implanted directly into human minds by a cause that is the creator of the human mind, the creator of reality. Bostrom, and other simulation theorists, argue the mind-implantation source is advanced human and/or non-human civilizations, but we will find in this paper that no beings of any sort can have ordinary spatiotemporally extended bodies (from premise 1 of the implantation argument), the mind-implantation source cannot consist of any embodied sorts of beings as that,

7 I borrow the term "mindscreen" from film studies (which is, to my knowledge, where it comes from) to use, expand, and rework the term for the philosophical purposes of this article. Kawin writes: "A mindscreen is a visual (and at times aural) field that presents itself as the product of a mind, and that is often associated with systemic reflexivity, or self-consciousness" (Kawin 1978, xi). "Film is like a dream - but whose? One rests in the dark, and sees; one is silent, and hears. One submits to the dream field, yet actively scans it - for play, for release, for community, solitude, truth" (Ibid. 3). 
and where only an other-than-spatiotemorally extended preternatural cause, a creator-God, can create the (seemingly, to some extent, spirit-like ${ }^{8}$ ) innards of the mindscreen, which are replete with directly witnessable and experienceable ethereal, spirit-like phenomenological entities such as qualia and feelings. The creator-God-as-simulation-creator appears to be described in the Bible in Luke 11:39-40: "And the Lord said unto him, Now do ye Pharisees make clean the outside of the cup and the platter; but your inward part is full of ravening and wickedness. Ye fools, did not he that made that which is without make that which is within also?"

If spatiotemporally extended external reality is in fact an inner mindscreen simulation, the inner mindscreen would require a creator (since representationalism would not be its source), wherein the Luke 11:39-40 would be describing a type of simulation theory (simulation theology). If a creator-God creates the inner mind of a human, then in order to avoid overdetermination, an external physical reality could not in any way also be the cause of the mindscreen of the internal human mind: mindscreen reality can only be nonrepresentational, and only can be caused by some other entity, being, that is not a spatiotemporal creator-being (this is the point that previous simulation theories miss), that is outside of and in some way apart from any mindscreen reality, that is the creator of mind. If the external-spatiotemporal is actually an inner mindscreen created by a preternatural creator, then that preternatural creator is the creator of known-reality (an omnipotent and omnicausal creator-God). This would mean that theologies which involve the creator-God having maximum sovereignty (creator of all), such as Calvinism, would involve simulation theory, lest they contain the aforementioned overdetermination problem. Bostrom, in his now famous article on simulation theory (2003), did not entertain the idea that the simulation is implanted by an omnicausal creator-God, the mystery beyond thingness (outside of any mindscreen), which would be a simulation theology, or what can be called a virtual reality implantation theology: experience of an external physical reality is not caused by the ostensible external physical reality it

8 From internal, inner-directed analysis of inner-consciousness, what are usually termed inner contents of consciousness, often appear like nothing in external, physical reality, when directly observed via introspection, and typically with qualities that are inverse of what is exterior. Searle writes, at the start of his famous book,

Compared to mountains and molecules, consciousness seems "mysterious", "ethereal", even "mystical". Consciousness does not seem to be "physical" in the way that other features of the brain, such as neuron firings, are physical. Nor does it seem to be reducible to physical processes by the usual sorts of scientific analyses that have worked for such physical properties such as heat and solidity (Searle 1977, xii). 
appears to be caused by, and rather it is a purely virtual reality mindscreen injected into mind. Bostom's famous "Simulation Hypothesis" (2003) concludes that other advanced civilizations create mindscreen reality, but in this paper we will find that leads to a reification fallacy (the inner-imaginary represents, indicates the external-nonimaginary), and only by concluding that God creates virtual mindscreen reality can we arrive at a consistent model of what human experience is.

\subsection{Bostrom's Simulation Theory is a Reification Fallacy}

Before we discuss why the failures of Democritean atomism, and also of the philosophies of atomlessness, reveal that the inner mindscreen cannot represent an externality containing spatiotemporal extensions, I will discuss the problems with the previous versions of simulation theory, and why simulation theory must be a simulation theology in order to be consistent. ${ }^{9}$

Vernes writes, “Although thousands of works have been published on the philosophy of knowledge, philosophers have not yet managed to come to a consensus on the fundamental issue: is there a reality that exists outside of consciousness and, if so, how can we prove it?" (Vernes 1999,1$).{ }^{10}$ If it is unproven and unknown if the external reality is real, is actually out there, then why not follow the evidence where it leads, and develop philosophy (and theology) accordingly? If simulation theory were true, we would expect to come to precisely what we have for thousands of years: that we cannot prove the external reality is there, outside of us. If the external and separated (distanced) spatiotemporal reality is replete with paradox, it delivers an incorrect model of reality, and perhaps its fiction also

9 The problems with the previous simulation theories discussed in this section apply to both original simulations and subsimulations (such as, mindscreen simulations creating yet more simulations). In other words, regardless if a mindscreen is an original simulation created by God, or a simulation created by another simulation, we will find in the next section that all mindscreen simulations are only created by God, and any simulation theory that does not espouse that view falls into contradiction.

10 This is a topic that has been pervasive through thousands of years of philosophy. Mounce writes:

Newton differs from Descartes. .. in his conception of science as in his particular scientific views... Descartes wishes to begin with the essence of matter and on this basis proceed to explain its particular features. Newton's point is that this misconceives the method of physical science. We cannot begin with the essence of matter, for it is not disclosed. We can begin only with matter as it appears to us, with material phenomena, which do not reveal their ultimate nature. (Mounce 1999, 17). (Emphasis mine.) 
engenders buried and deeply (but illusorily) intuited solipsism, all of which is done-away-with by the logic of the implantation argument.

Perhaps the most obvious account of a simulation theory before the modern time would be the Indian Buddhist, Dharmakirti, ${ }^{11}$ and perhaps philosophies such as Parmenides can be interpreted as a simulation theory. But Descartes' brainin-the-vat seems to be the first account that is explicitly a simulation theory, involving a description of consciousness as created and controlled by (implanted by) another consciousness, and where the mindscreen-self believes its mindscreen cinema represents spatiotemporal externality but where it does not. Both the older and the newer simulation accounts do not reveal that only a creator-God can be the maker of a mindscreen. For Descartes, it was a demon who creates the simulation, and the recent and modern spectrum of simulation theories, such as with Phillip K. Dick (see Wittenkower 2011), Bostrom (2003), Baudrillard (1994), and that of the popular 1999 film The Matrix, are dominated by the idea that the mindscreen is created by technological beings, none of which, to my knowledge, are virtual reality implantation theologies, as this paper shows is the only coherent option. ${ }^{12}$ The recent spectrum of simulation theories, popularized by Philip K. Dick and brought into academia by Hans Moravec, Nick Bostrom, among others, involve the idea that the simulation is caused by hypothetical humans and/or advanced civilizations, but where the italicized word, "hypothetical", involves a reification fallacy, as follows: according to simulation theory, the simulation (the virtual mindscreen) is mind-dependent, and cannot be known to be representational of any existence of any sort beyond (outside of) the virtual mindscreen, but elements of the simulation nevertheless are assumed representational, and are used to make conclusions about an external reality beyond the simulation (Descartes' hypothetical brain-in-the-vat demon involves the same sort of reification fallacy). This reification fallacy is specifically as follows: if inner then outer, not outer, $\therefore$ inner, I $\rightarrow 0, \sim 0, \therefore$ I (nonlogical). Or, in other words: If I feel that the inner mindscreen contents represent (I), then I can know they represent the outer (the hypersimulational) (O), but I cannot know they represent the outer (the

11 Dreyfus (1997), 85.

12 One of the rare articles to discuss theological issues and simulation theory is Steinhart (2010), where Steinhart says simulation theory proving the existence of God is "an overreaction" (23). Steinhart's analysis falls into the aforementioned group of simulation theories, interpreting simulation as created by advanced beings, rather than a hyperspatiotemporal cause, and therein inner reifying mental contents (simulation mindscreen contents), such as inner concepts that things like computers, universes, etc. exist, as if they also represent the hypersimulational (reification fallacy). The hypersimulational is unknown except by special and perhaps ineffable circumstances, see discussion below about revelation. 
hypersimulational) $(\sim 0)$, therefore I feel that inner mindscreen contents represent (contradiction).

Bostrom and other simulation theorists tell us that the hypersimulational/hypervirtual realm (that which is beyond, or outside of the mindscreen) is very much like the simulation contents, and the very same sorts of beings and activities exist in both: since the virtual mindscreen simulation contains Ilike entities then so does the hypersimulational realm. In different words, what Bostrom and others do is assert that since the mindscreen reality, the internal cinema, contains and involves specific types of cinematic elements in the mindscreen mental contents (other humans, advanced beings, technological progress, etc.), we can therefore know that is how circumstances also are hypersimulationally - as if my having a dream (internal only) about an extraterrestrial civilization last night indicates that I can know that the extraterrestrial civilization actually exists mind-independently (externally). How can the non-representational be used to represent? How can the inner-only be claimed to describe the outer-only? Just because my mindscreen has thoughts about advanced alien civilizations does not mean I can conclude that existence is anything like that outside of my mindscreen. Using mindscreen contents to explain the mindscreen's cause is the logical error that Bostrom's and the other contemporary simulation theories involve, but which the implantation argument does not involve. What Bostrom and other simulation theorists are doing is asserting that the mind-dependent virtual reality (mindscreen) contents are implanted, wherein they are analogous to a dream (nonrepresenting), but from the dream we can nevertheless know that the sorts of beings creating our dream: since I have dream beings in my dream, that must be how the non-dream world is (e.g., if there are advanced civilizations within the simulation contents, then there are also such advanced civilizations hypersimulationally), wherein that which is mind-dependent is also mind independent (contradiction).

As stated, it appears this involves some variety of the critical thinking fallacy called the reification fallacy, or the fallacy of misplaced concreteness, which occurs when an imaginary item is treated as if it were a concrete and real (non-imaginal) aspect of mind-independent external reality. In Bostrom (2005), he writes: "We have very little understanding of the psychology or motivations of our hypothetical simulators (who would surely have to be an extremely advanced life-form in order to be technologically capable of creating ancestor simulations)" (93). How do we know that the simulation creators Bostrom is referring to even have something recognizable as "psychology"? Unless Bostrom can see them (outside of his mindscreen), he is purely inventing the idea, assuming that since he has a thing called "a psychology", then so do his simulators. He may not be able to imagine other than that (beyond the concept of "psychology", especially in his way of 
understanding it), but his simulators may be well beyond that, and well beyond his imagination (outside the concepts available to him in the mindscreen he has been offered). Bostrom is using what is imagination (simulation's contents not known to represent an externality) to make conclusions about what is nonimaginal (the hypersimulational) - reification fallacy. In his simulation hypothesis, Bostrom disproves the key ingredient he assumes is correct: he disproves the outer is a known (disproves that mindscreen represents: we are only simulants), by assuming the outer is real (that it does represents: we know we are simulants because of what the mindscreen contents tell us [that there are advanced beings with technological progress]) - which is like believing the contents of a dream represent $(R)$ a reality external to the dream, in order to show that only the dreamcontents are known, they do not represent $(\sim R)$ a reality external to the dream $(\mathrm{R} \wedge \sim \mathrm{R})$ : the outer creates the inner so that the inner can reveal that there is no outer (contradiction). Only within the mindscreen can be known, but conclusions are made by Bostrom (and the other contemporary simulation theorists) about what is beyond (not within) the mindscreen: the not-representational is held to be represented (contradiction). ${ }^{13}$ Bostrom is claiming that (A) the simulation-bound mindscreen reality (containing mindscreen contents about advanced civilizations, progress, universe, technology, etc.), is (B) largely about concepts that are also of the hypersimulational outer-reality (not simulation-bound). This is the contradiction that the contemporary simulation theories involve: they formulate the idea of the mindscreen simulation based on and dependent on the unknown hypersimulational domain: that which is simulation-bound is known via the not-simulation-bound - like knowing the exclusively-within by knowing the exclusively without $\left(\mathrm{W}^{\wedge} \sim \mathrm{W}\right)$. To put it in earlier, Cartesian terms: How can the brain-in-a-vat even know there is a brain that is independent of the mindscreen, since the brain is part of the mindscreen simulation? Perhaps mind-in-a- "vat", for lack of better words, but how does a mind know there even is a thing called a "brain", or a "vat", beyond, in the mind-independent realm?

13 According to the formulations of this article, the only way a human could know something beyond the virtual mindscreen reality is if the mystery-creator of mindscreen (God) reveals it to the consciousness - call this revelation. The conclusions of this paper lead to the idea that such a revealing could not be anything that appears like the contents of mindscreen simulation and its mind-independent extended spatiotemporal surfaces, lest the same reasoning used in this article to conclude that those are only of the simulation (virtual picture-screen contents that do not represent) found in this article apply to revelation. For that reason, any revelation of the hypersimulational would apparently be beyond language and cognition, and beyond the concept of thingness - the end of all things. Perhaps this is why people of the Bible had paralyzing fear when witnessing angels and God (Mt. 17:6, 28:4): they were seeing what is beyond known thingness. 
How can this inner-to-outer move, that Bostrom and the contemporary simulation theorists make, be warranted? Yet this inner-to-outer reification fallacy is freely made by philosophers, just as it is with the average person in their daily existence, believing their mind-enclosed mindscreen represents a mind-independent externality, who presumably do not discuss this move, nor dimensionless-atomism's consequences, nor simulation theory - which allows realist (and naïve realist) philosophy and science to exist. For example, Chalmers, in discussing Bostrom's simulation hypothesis, also ventures into reification fallacy territory in the following passage, assuming the basic structure of reality found amid the simulation, its general concepts, are accurate and real (parallels and therein to some degree represents the actual reality outside the simulation), in order to make conclusions about the hypersimulational reality: "The Matrix Hypothesis is one that we should take seriously. As Nick Bostrom has suggested, it is not out of the question that in the history of the universe, technology will evolve that will allow beings to create computer simulations of entire worlds... Whether this is right or not, it certainly seems that we cannot be certain that we are not in a matrix" (Chalmers 2005, 134).

If we don't know what is outside the mind, how can we know or even theorize that there are entities describable as "advanced civilizations" outside the mind in the first place? What if external reality was entirely different than even that? Bostrom's thesis involves imagining ultra-advanced civilizations that can create inner phenomenological mindscreen contents, such as awareness and consciousnesses, with feelings, thoughts, inner picture-screen digital imagery, qualia, and so forth - some of which are seemingly hard for us to even define, let alone create or manufacture, so in such a situation as advanced as that, how do we know that reality is even familiar to the way we believe it is? What if the (simulationbound) concept that there are ultra-advanced technological beings, such as those Bostrom and others discuss, is not at all descriptive of what reality is like outside of the simulation? It is not difficult to theorize plausible examples of such beings, that are completely different than being "advanced civilizations". Perhaps the simulation-creating beings of Bostrom's theorization do not have energy releasing bodies, where another medium, perhaps that is a free-energy medium, is used to hold and/or generate the simulation mindscreen consciousnesses. The beings need not necessarily have progressed or evolved to that point. Perhaps this is just how they were created, by whatever process it was that led to their coming into being, in a dimension, reality, universe, or whatnot, little understood to Bostrom, where the beings do not need technology or to seek energy-intake to sustain their existence, and, where they only have interest in futuristic mindinebriating and mind-intensifying philosophical entheogens, of some sort, that are harmlessly available to them in their reality, and therefore they have no 
interest in technological progress or any progressing of any sort in their existence, since they only want to be still and know the ecstasy of their inebriations. And their minds could be structured in such a way that their imaginations can create landscapes and worlds (perhaps aided by the entheogens), but where their imaginations contain internal semi-autonomous simulation-streams, that can "bud" groups of self-aware mindscreens internally, existing as seemingly autonomous simulants that are purely virtual realities that simulate minds and worlds, functioning as dependent sub-mindscreens that are self-conscious amid the worlds of these creatures' minds, where the sub-operations involve perhaps very different landscapes as compared to the host mind (where one of the submindscreens could be Bostrom, or me or you) but with a qualia copy of the host (that is, Bostrom's qualia and his simulator's qualia are copies of each other, in the case were such beings would have qualia). What would be the motivation for such creatures to internally create such simulated worlds (if they don't happen spontaneously)? Again, it is relatively straightforward to theorize plausible reasons, one of which could be that the simulation-creating beings are creating copies of aspects of their subjectivity, where this copying or doubling process generates ecstasy (which these beings are apparently very interested in and dominated by), since according to some, such doubling of one's consciousness leads to ecstasies. ${ }^{14}$ Why Bostrom would conclude that concepts bound to his simulation (such as, that there are things called "advanced beings") can give indications about what is outside of the simulation (advanced beings)? Bostrom is making hard conclusions about a reality completely unavailable to him, as he has no reason to conclude that simulation contents reveal the nature of the hypersimulational realm, but his simulation hypothesis makes conclusions based on the hypersimulational.

14 This is a predominantly Christian idea, to my knowledge, where self-replication is associated with God-ecstasies. God-Christ created images of himself (people) for his enjoyment (Gen. 1:26, Col. 1:16-17, Rev. 4:11). And Stang, in his book (Stang 2016) discusses multiplicity of self and mind, including cases of dividing of self and mind, whether considered a close-twin self, an exact copy, and so forth, can have the quality of the ecstatic when realized in awareness. In discussing a breaking and splitting of self, Stang writes:

But what if this was. .. revelatory or the very nature of selfhood...?... The self is not one half of the pair... but rather the pair itself... For Dionysus, eros or love for God propels the self to stretch to the point that it splits in two, in ecstasy, and thereby opens itself to the indwelling of the unknown God as Christ. Dionysus takes Paul as the exemplary lover of the divine, and his confession that "it is no longer I, but Christ who lives in me" as testimony of Paul's suffering the ecstatic indwelling of Christ (Stang 2016, 7-8). 
Bostrom's “Simulation Hypothesis" (2003) is unquestionably the most widely discussed account of simulation theory in the literature, and more recently has been widely popularized by celebrity billionaire businessman, Elon Musk. There are some similarities between the implantation argument and the varieties of the simulation theories, such as that all involve the idea that humans are not actually in the bodies they believe they live in, that humans are not actually living in the physical external reality they believe they are in and see all around then, and that their lives are a mindscreen simulation created by another more advanced mind. But the implantation argument differs from the rest in that the implantation argument for the existence of God does not involve the circular reasoning of trusting in the contents of the simulation to discover there is a simulation (reification fallacy). Instead, the implantation argument unveils a fatal internal system problem inside the matrix, so to speak, revealing that the external spatiotemporal reality is impossible, that it can only be a simulation that cannot represent anything externally real (mind independent), and that something not at all of the mindscreen's contents, wholly supernatural (wholly outside of the mindscreen, which is the key difference between the implantation argument and the other simulation theories), must be the creator of the mindscreen simulation, which is the reason that the self can only be a God-implanted virtual mindscreen. Bostrom wants to use the outer in order to understand the inner, when he does not know anything about the outer to begin with. The reason that implantation argument avoids those problems is because the other simulation theories use familiar concepts, those found inside the simulation content, in order to theorize about what is hypervirtual/hypersimulational - about what is outside the simulation, which leads to the aforementioned reification fallacy. Only by specifically maintaining that the hypersimulational cause of the simulation is mystery, as the implantation argument does (God is mystery), is this fallacy avoided. ${ }^{15}$ In different words, the previous simulation theories use what appears, what is witnessed (mindscreen content), to conclude about what does not appear, what is not witnessed (reification fallacy), whereas the simulation theology of the implantation argument uses what is witnessed (mindscreen content) to show an internal fissure inside the system of mindscreen content (neither atoms or atomlessness

15 The only iotas that the hypersimulational creator (God) of the simulation would reveal about that which is hypersimulational seemingly would consist of hyperthingness (the end of all things), and seems best labeled as "total mystery", as compared to the ostensible extensions of the mindscreen simulation, since the hypersimulational would be hyperspatiotemporal and likely ineffable. Colossians 2:2: that their hearts might be comforted, being knit together in love, and unto all riches of the full assurance of understanding, to the acknowledgement of the mystery of God, and of the Father, and of Christ (itals added). 
can account for a mind-independent mereological reality) if the mindscreen is interpreted as spatiotemporally external and separate rather than mentationally internal and simulated. The simulation content cannot reveal anything that is beyond the mindscreen, and the hypersimulational (supernatural) cause of the mindscreen must be unknown (mystery) other than cases of supernatural revelation, which are beyond the scope of this paper. The implantation argument does not assert to know the unknown, to know the hypersimulational, which is the fatal error of the other simulation theories. How can that which is undetectable (the is hypervirtual/hypersimulational) inform about that which is seen and detectable (simulation contents)? What Bostrom is doing is assuming that since the only possibility is that the simulation contents must be astonishingly similar to the hypersimulational, as if we should assume that the only thing that civilizations that advanced civilizations would simulate in creating mindscreen simulants would be to simulate realities that are very similar to their own. Regardless, even if that were to happen, to make the jump from inner to outer, to knowing the outer from the inner, is to make the jump of a reification fallacy: to claim to know the unknown from the known (to know what is witnessed from what is not witnessed).

\subsection{The Creator of the Simulation Reality Can Only Be God}

Created simulations (those that were caused to exist) can be the creators of subsimulations (simulations creating simulations, as the example of the entheogen-lovers involved), but both simulations and subsimulations would be under the control of the creator of simulations. This is because if the creator creates a mindscreen that is not a subsimulation of an original simulation, call it mindscreen $_{0}$, which in turn creates (subsimulates) another, mindscreen ${ }_{1}$, which subsimulates another, mindscreen ${ }_{2}$, and so on to mindscreen $_{\mathrm{N}}$, if the creator is the controlling originator of mindscreen $n_{0}$, and mindscreen $_{1} \ldots$ mindscreen $_{\mathrm{N}}$ are subsimulations within mindscreen $n_{0}$, then $\operatorname{mindscreen}_{1} \ldots$ mindscreen $_{\mathrm{N}}$ would merely be subprograms (for lack of better words) of mindscreen : $_{\text {: }}$ the creator-God would be in control of any and all simulations as well as their subprogramsubsimulations. ${ }^{16}$ And of the set of all mindscreen simulations that are not subsimulations, if none are of them are self-created, and if none are uncaused

16 Free will, if it exists in any mindscreen simulation reality, would not affect that the creator has control over a simulation. If the simulation creator deemed to include free-willed mindscreen events in the created simulated reality, if such were possible, creating a pocket of irreducible nonpredictiveness of a free will event, that would be an instance of the creator being in control, since the mindscreen creator creates and allows such happenings, and could presumably alter and remove those pockets at any time of desired. 
(have always existed), then the cause of any of the mindscreens would be outside of the set of all mindscreens. What is spatiotemporal and naturalistic (such as spatiotemporal extensions) is only an aspect of the internal mindscreen consciousness, and the creator, being hypernaturalistic (supernatural, God), is the

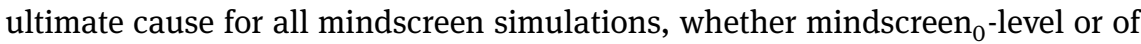
any $N$ th level.

Since the implantation argument contains the idea that any reality of spatiotemporal objects is only mind-dependent, then there are no spatiotemporally embodied beings, in any ordinary sense of having a spatiotemporally extended body, and whatever the mystery-being is that is the mind-implanting preternatural creator (God), that creator cannot have any sort of spatiotemporal body in the ordinary sense - which explains why the entheogen-loving free-energy embodied beings discussed above, or why Bostrom's advanced beings (which are embodied), cannot act as simulation creators - they can only be simulations or subsimulations. Some have jokingly stated that God could be a teenager living in his parent's basement running simulations in some futuristic civilization, ${ }^{17}$ but not only does that involve the reification fallacy, as pointed out in the previous section, but further, that comment was made referring to simulation creators as being embodied teenagers, but as just stated, there are no embodied beings in the ordinary sense (such as with a human teenager) according to premise 1 of the implantation argument (which is confirmed in the next two sections). Rather, a cause that is entirely hypernaturalistic (supernatural), and in some ways beyond thingness, seems to be required to be the originator of the simulations, since external spatiotemporal extended bodies involve aporia, and since the creator of the simulations would not be among the set of all mindscreens. And for any

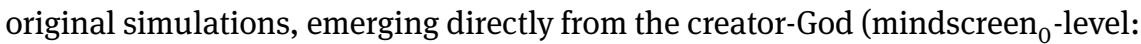
mindscreen simulations that are not subsimulations), it would appear that those, also, can only be created by the very same preternatural simulation source, where there is only one source for all original simulations as well as all subsimulations, for the following reasons explained next.

17 One place where this was mentioned was in a YouTube video called "Do We Live in a Simulated Universe", at the World Science Festival YouTube Channel, that was posted December 16, 2013, where in talking to Richard Dawkins, the famous physicist, Brian Greene, suggests that God may be something like a teenager from the future. This involves the same reification fallacy as discussed in this section: since my simulation (mind-dependent) involves things called teenagers, therefore the hypersimulational must also (despite being completely outside of the evidence available to me in the hypersimulational reality). 
The mindscreen, being the totality of human reality, has two major divisions: inner (feelings, thoughts, qualia, etc.) and outer (what is believed to be external, such as spatiotemporal extensions). Is a feeling a thing? It seems so, but not in the same way a brick is. The brick and the feeling arguably have inverse thingness and inverse properties from each other, where outer things are describable with shared language, ${ }^{18}$ and the inner things, such as a feeling which is seemingly largely ineffable, are not describable with shared language. The brick is a picture within the mindscreen (usually mistakenly believed to be mind-independent and external), and describable with shared language. But what is most notable is that what is believed, erroneously, to be outer (external and spatiotemporally extended - not a cinematic inner mindscreen) is in fact inner, and according to the implantation argument, leading to the conclusion that there is only innerness in what is known or knowable, in any reality.

Regarding the hyperspatiotemporal creator-God of all simulations and subsimulations, it is difficult to assert much about the creator, lest we fall into a reification fallacy. But while we don't want to assert that our mindscreens represent the hypersimulational, as Bostrom and the other simulation theorists do, leading to a reification fallacy, it does seem a different matter to conclude that logic will hold in both the mindscreen realtiy, and the hypersimulational, where, for example, $2+2$ equals 4 in both realms. If that is true, then the creator cannot be a mereological item composed of spatiotemporal extensions, due to premise 1 of the implantation argument, where the fatal problems with atomless gunk and Democritean atomism that will be revealed in the remaining sections would hold in both the simulational and the hypersimulational realms. There is a long tradition in philosophy of describing that God is a point (partless, unextended), but I am not necessarily holding that view. What I want to assert is only that the creatorGod, who is hyperspatiotemporal (supernatural), and outside of the mindscreens, is in some ways ineffable (not describable via language that is replete with mereological or spatiotemporal references), the creator is an uncaused causer, and the creator is some sort of One, since the creator does not have spatiotemporal properties. If one were to assert there are multiple such uncaused causes of mindscreen simulation realities (that there are multiple uncaused creator-gods), their lack of spatiotemporal properties and mereology will make it very difficult to differentiate them in the hypersimulational realm: if there were two uncaused creator-gods, that are non-spatiotemporal, they could not be distinguished by location, size, color, and so on, so there would be no known ways to distinguish them, and it would more straightforward to hold that there is, instead, just one presence in

18 Shared with other simulants perceived in the mindscreen who are either only picture images, or other mindscreens that God gives pictures of, as an outer appearance. 
the hypersimulational realm acting as creator: there is only one God and God is one. ${ }^{19,20}$

God, as just described, appears to be the creator and sustainer of all realities (mindscreens), and who thereby is omnicausal, seemingly the creator of all realities, omnipotent, all-knowing, and omnipresent. ${ }^{21}$ The simulation creator, according to what we have arrived at to this point in this paper, would be more like a Spirit, being outside of the spatiotemporal and therefore nonphysical (not of spatiotemporal matter-extension, nor part of the mindscreen's feigned spatiotemporal ingredients), as well as being eternal and/or not narrowed-down-to the time-stream of the simulation mindscreen. Also, in creating the simulation, the creator-God is before all simulations, and before all time (all mindscreen time). Being before all things (all realities: all mindscreens), this creator-God appears to exhibit divine perfection, being a being that seemingly cannot have anything added to it, since all realities come out of it, and seemingly a being that we cannot conceive of one greater than. And if this creator-God exhibits absolute perfection, as the previous sentences seem to imply, then what God creates can only be distinct from God and necessarily imperfect (1 Cor. 15:42), since that which is not God is not perfect and necessarily corrupted. A matter of logic reveals why the perfect creator-God can only create universes with pain and corruption (solution to the problem of evil). Furthermore, the creator-God, if the perfect One, need not create anything, since the creator-God is perfectly complete, and since nothing can be added to an absolutely perfect God (Eccl. 3:14), where creating anything is of no benefit to God, then God, in creating, acts solely for the other, gaining nothing in return, which is to act as pure and maximal sacrifice of total love - which is the defining mark of God as defined in the Judeo-Christian tradition. Note that since

19 Deuteronomy 6:4: “God is one”. If hypersimulational beings have bodies, they would have them in a supernatural way that is ineffable from the perspective of the human who works from the perspective of the mereological and spatiotemporal (from the perspective of the mindscreen). 20 The Bible involves this sort of line of reasoning, where God is known (John 17:3), but where God is also beyond understanding, and not of the spatiotemporal, being a Spirit (John 4:24). Ephesians 3:3: "the mystery of Christ"; Isaiah 55:8: "For my thoughts are not your thoughts, neither are your ways my ways, saith the Lord"; Deuteronomy 29:29: "The secret things belong unto the Lord our God: but those things which are revealed belong unto us and to our children for ever..."

21 When the creator of the simulation creates it, the creator is interacting with what is created, and therefore to interact with it, he is seemingly where it is (omnipresent with what is created), in some way or another, either in influence and/or presence amid (inside of, coinciding with) the created mindscreen activity, whereby some sort of omnipresence of the creator in the mindscreen exists. 
nothing can be added to God, that maximal sacrifice of pure love only has direction from God to person (to mindscreen), where there is nothing any created entity can do to cause God to create or do anything at all: God is the sole reason and the impetus of all creating of any entity that exists. And since nothing can be added to God, or paid back to God, the maximal sacrificial love of the creator-God is freely given (by Grace) to the created entity, such as to a mindscreen, where any mindscreen is created via pure sacrificial love - again, the mark of the Judeo-Christian God: from premise 1 of the implantation argument, we arrive at the existence of the Judeo-Christina God. The only way any created entity (mindscreen) can exist is if it is created by the maximally giving and sacrificial love of the creator-God who maximally gives of self, (dying and) living for and as other, which is ecstasy (ekstasis). Stang, in discussing Paul, who no longer lives, but it is Christ who lives in him (Galatians 2:20), writes of the imitating-ecstasy of God within: "As a true lover, and beside himself [in ekstasis], as he says, to Almighty God, and not living the life of himself, but the life of the Beloved" (Stang 2012, 1).

From the implantation argument, and the straightforward discovery that the spatiotemporal extensions that are believed to exist externally cannot be dimensionless atoms and therefore cannot be external, we can derive the conclusion that reality is mindscreens (realities) are only created via perfect love and sacrifice by the Judeo-Christian God, and exist in that creator-God. ${ }^{22}$

22 There is a second way that simulation theology points to specifically the Judeo-Christian God. The implantation argument shows that what is known is apparently inner (outer spatiotemporal externality is never experienced as outer), so to know God is via the inner, which is a specific characteristic of the Judeo-Christian God, who is the inner God, the God of innerness: "behold, the kingdom of God is within you" (Luke 17:21), "Let this mind be in you, which was also in Christ Jesus..." (Phil. 2:5), "I am crucified with Christ: nevertheless I live; yet not I, but Christ liveth in me..." (Gal. 2:20), "He that abideth in me, and I in him, the same bringeth forth much fruit" (John 15:5). What is meant by "innerness"? That there is no representation, and that there is no separation of experiencer from what is experienced, all that is known is known directly, since there is no inner-outer divide to cross via the impossibility of representationalism. Phenomena are intimate, they are not separated from the person, self is the inner mindscreen, imbued with the feeling of innerness of reality when awake to that self is a mindscreen, and where that realization is associated with revelation of the creator-God (see Conclusion). Believing one is experiencing an externality is to live separate and to suffer. But to see clearly is to know is only innerness, and according to the Judeo-Christian tradition, that all is inside the God of innerness (Christ) (Col. 1:17), who is a Spirit. God apparently only sees humans as innerness, inwardly, not an externality, 1 Samuel 16:7: “... for the Lord seeth not as man seeth; for man looketh on the outward appearance, but the Lord looketh on the heart". "The man Jesus constitutes nothing less than the inner life of God, the very place where God's trinitarian relatedness is play out before the world” (Webster 1991, 17-18). Bassett and Greathouse write: "Like Gregory of Nyssa, Augustine is certain that we meet God most truly and in the most revolutionary fashion within ourselves... 'You were more inward to me than my most inward part, and a higher than my highest' (Confessions 


\section{Any Ultimate Reality Cannot Cause Experience of a Physical External Reality}

The simulation theory and simulation theology is arrived at because experienced spatiotemporal extended magnitudes cannot exist externality, and instead must be virtual images of the internal mindscreen only. When we look out at external physical reality, we believe we experience extended magnitudes and matter objects that are mind-independent. We can perceive and/or conceptualize the division of various spatiotemporal magnitudes (of time, matter, or space) into smaller parts. The question is if we can divide extended chunks of physical reality all the way down to partless atoms (simples, Greek atoms, philosophical atoms). If the answer is no, then physical external reality would be filled with extensions, any extension would have proper parts, would be divisible everywhere (unless there are indivisible extended atoms, see the next section), and would be extended, despite infinite divisions (infinite divisibility). Much like any extended piece of the real number line can be split with infinite divisions, divisions everywhere, but where in the series of dividing one can never "arrive at" a last division, nor "arrive at" an unextended segment of the number line, the same can be believed of extended matter, where there is no need to believe that external magnitudes can be divided down to the partless philosophical atoms. This anti-atomic theory (atomlessness) has been called "atomless gunk" by Lewis (1991, 20), and this is the name it often goes by in current debates. According to this philosophy of atomlessness, any physical object, duration of time, or any topological region, is further reducible into more fundamental parts, where even infinite divisions do not reveal that the extension is composed of dimensionless-sized fundamental building blocks (See Pyle 1995, 2-4). Since the infinitely divisible extended matter always remains extended, without dividing "down" to philosophical atoms, it has been asserted that the infinite divisibility of atomlessness (atomless gunk) supposedly allows for extended matter without the mysteries of Zeno's metrical paradox of extension, avoiding the contradiction of how humans live in a world of extended surfaces being composed of dimensionless atoms, which leads to the implantation argument. Atomism - and in particular dimensionless-atomism - is in conflict with the belief that there is a physical external reality of extended magnitudes, where philosophies of atomlessness have been sought to rescue the

iii.11)" (Bassett and Greathouse 1985, 90). God is a Spirit, and Spirit comes from the innards, is of the innards. "The Spirit is breath... and ... he wishes only to breathe through us, not to present himself to us as an object”... The Spirit is not a "what”... Balthasar's formulation[:] the Holy Spirit is. . . the non-objective-eternally-beyond-all-objectification-breathing mystery... . (McDonnell 1998, 222). 
situation, by avoiding premise 1 of the implantation argument. For example, writing in the context of atoms being dimensionless atoms, Simons writes, "Atomless mereology and topology are considered by their proponents to confirm more closely to our experience, which is always of extended items and not of atoms. The philosophical gain is thought to compensate for the loss of atomism's simplicity" (Simons 2004, 374). This is to have faith in the realist intuitions of empirical experience as having some degree of reliability (there really are extended magnitudes outside of my mindscreen, represented by my mindscreen), but further, it has also been believed that the varieties of atomlessness and atomless gunk are also sufficiently logical, to the point of overcoming atomism. These reasons are probably why the simulation theology of the implantation argument has not been deduced previously. In what follows, we will find a fatal flaw in the philosophy of atomlessness, where the flaw reveals that only dimensionless atomism is thinkable for any external reality, wherein the mindscreen does not represent an externality separate from the mindscreen, and the implantation argument's first premise is established, leading to its conclusion that God exists.

Infinite divisibility (atomless gunk) involves the concept that extended matter is divisible extended matter, where the divisions of the extended matter are mind-independent, and therefore infinite divisions exist mind-independently in any extended spatiotemporal object. For this reason, extended matter could be better referred to as being infinitely divided, rather than infinitely divisible. When dividing an extended matter object - say, for example, a smooth surface of water - as we divide the water surface into smaller and smaller segments we will arrive at the level of the water molecule. We can continue dividing after that, wherein we will divide into either smaller molecule segments, and eventually into scientific atoms (and by that I mean the "atoms" that scientists refer to, which have proper parts [electron, proton, etc.], not the partless Greek atoms, or philosophical atoms discussed above ${ }^{23}$ ). Notice that we do not say that we have created the atoms by our dividing the molecule down to the scientists' atom, but rather, the atoms already existed, with boundaries separated from what is different from what is surrounding it. Dividing-up the molecule down to the scientific atom, and therein

23 The word "atom" is used in academia in two ways: to describe a unit of composite matter, which are the atoms that scientist discuss, composed of parts (quarks, etc.), and secondly the basic building block, the unit of partless reality, or philosophical atoms (Greek, atoms), which philosophers discuss. Philosophical atoms compose scientific atoms, and the use of the word "atom" by scientists is result of an error in believing that the discovery of the scientific atoms was the discovery of the philosophical atom, though it is often claimed it has. It is not clear if science has yet discovered philosophical atoms. 
considering its proper parts, is merely a way of discussing divisions of reality that already exist. Either every magnitude is presently divided everywhere or there are extended parts of the magnitude that are indivisible, which would be extended atoms. Either atomless gunk is infinitely divisible everywhere, or it is not infinitely divisible everywhere and not atomless gunk (it has zones that are indivisible) and contains atoms. So atomlessness only involves any extended magnitude being infinitely divisible everywhere. If I cut a hunk of meat, I am not observing something that is seamless, without proper parts, like an enormous partless philosophical atom; rather, if I cut up the meat I am merely separating its preexisting divisions and cells in specific locations, and in the cases where I cut through the middle of a cell, I am merely separating organelles and such. And when I divide the organelles into molecules, and the molecules into scientific atoms, in each case, I am not creating divisions - the divisions already existed. In other words, if there are no extended atoms, then mind-independent matter is already maximally divided according to atomlessness, containing infinite preexisting non-mind-dependent divisions.

The reason for discussing all this is because, from what I can tell, philosophers appear to routinely discuss infinite divisibility as if a dividing process is happening, that could go on forever, where one starts dividing an extended surface, as if creating the divisions in a process of infinite divisibility. Consider what Sider writes:

Borrowing a term from David Lewis..., let us say that an object is made of "atomless gunk" if it has no (mereological) atoms as parts. If something is made of atomless gunk then it divides forever into smaller and smaller parts - it is infinitely divisible. However, a line segment is infinitely divisible, and yet has atomic parts: the points. A hunk of gunk does not even have atomic parts "at infinity"; all parts of such an object have proper parts (Sider 1993, 287). (Itals added.)

It is very important that Sider mentions that the "hunk of [atomless] gunk" "does not even have atomic parts", since this, I will claim below, involves a fatal error for the gunk theorists, in that they are not allowing their hunks of gunk to be mathematically describable by the Real number line R. And to lead up to this problem, I believe it stems from how philosophers describe atomless matter as if they are doing the dividing, creating divisions, as if the hunk of gunk was not already divided everywhere, and thus contains extended (partless) philosophical atoms. Note that Sider writes "it divides forever into smaller and smaller parts", and he did not write that the atomless gunk is already divided in infinite divisions. "Divides forever into" could denote a dividing activity, not an already-divided-up non-activity (non-activity with respect to the divisions of infinite divisibility). He uses the word "divides", which is a verb (an activity), which can be taken as 
present tense, as if the dividing is a happening rather than a non-happening, a dividedness that exists rather than which could be carried-out. And Sider uses of the word "forever", a temporally-oriented word, which implies that perhaps all the dividing has not yet happened. This must be what Sider was intending, since he stated that the hunk of gunk is not in correlation with R. If a given gunkyatomless object at any stage in the regress has a magnitude, call it " 1 gunk-unit" (or just “1”), 1 is divisible "forever" (Sider's word): 1 is divisible into 1/2, 1/2 into $1 / 4,1 / 4$ into $1 / 8$, and so on, where the value of the fraction never reaches zero since the denominator never reaches $\aleph_{0}$, and thereby the parts of the extended gunky magnitude never reach a point-size or a final (atomic) division. Every fraction describing every stage of the gunk regress is a fraction with a non-transfinite number in the denominator. There are $\aleph_{0}$-many of these fractions, but the value of each of the $\aleph_{0}$-many fractions is greater than zero. Infinite divisibility is not a series of divisions or division activities, rather than a preexisting complete set of divided demarcations where every magnitude is divisible everywhere (which, we will see, involves dimensionless atomism ${ }^{24}$ ). There is never a last extension to divide, wherein we arrive at dimensionless points, and I believe this is what Sider is thinking - but this cannot be what an atomless hunk of gunk is like. Either an atomless extension that is infinitely divisible is not yet divided up and has uncut partless extended atoms within it (which is a contradiction), or it is maximally divided everywhere. The former is a contradiction, so only the latter is possible, but where that is a description of the $\mathrm{R}$ line - Sider is wrong, as are the remainder of the gunk-crowd, who seem to describe gunk in the non-mathematical way that Sider does. Notice how Perrett discusses infinite divisibility as an infinite regress, which the dictionary defines as "an act," "movement," or "to make or undergo", indicating a process of dividing, rather than a situation of preexisting dividedness:

24 Ehrlich $(2014,655)$, in discussing Zeno and Aristotle, puts this matter as follows, describes parts of their debate on this matter:

1. If a magnitude is divisible everywhere, then there is no impossibility in supposing it to have been divided everywhere. 2 . But if it is divided everywhere, portions will be produced by the divisions that must be either (i) magnitudes or (ii) points or other entities without magnitude. 3. If (i) is the case, then there are magnitudes that could be further divided, and that contradicts the hypothesis. 4. Alternatively, if (ii) is the case, then the magnitude has been shown to be composed of nonmagnitudes. 
Obviously, if the Necessity of Simples Thesis is true, then the actual world contains simples. Note too that if is this stronger thesis that the regress argument I sketched at the beginning 25 is presumably supposed to establish: i.e., there is supposed to be some logical incoherence in the notion that there could be an infinite regress of partite parts. Call this regress argument The Decomposition Regress: The process of decomposition of partite things into their parts cannot be endless; at some point we must come down to those fundamental impartite objects out of which all partite things are composed. (2004, 436-37) (Underlining added)

Note the use of the word "process" in Perrett's passage. But there is no such dividing process - all divisions already exist lest there be spatiotemporal extensions that are divisionless, containing extended partless philosophical atoms. Even the labels, "infinite divisibility", or "infinitely divisible", seem to imply this (nonexistent) process of dividing what is already divided. The dictionary definition of "divisible" is "capable of being divided", where the word "capable" indicates that the dividing has not happened yet. Philosophers suggesting a process, or activity, of "dividing down" infinitely are considering matter as being in something very much like an Aristotelian minima, with a division potential, but where the division process never completes (whereby it remains extended), and there is no transition from magnitudes to nonmagnitudes. But that does not mean that the divisions are not there, as the philosophy of the Aristotelian minima seems to involve. A hunk of matter, space, or time, does not need a human to do the divisions for them to be there, there is no potential dividing, since the gunk object is already maximally divided lest there exist extended atoms in it (which is what it seems not-fully-divided Aristotelian minima contain). A hunk of meat that is uncut is nevertheless replete with divisions everywhere, it is not an extended atom, and to suggest that it will have potential divisions that are not yet created (it has divisionless regions), seams that do not yet exist, perhaps some of which are created by the knife when the meat is cut, it to consider the hunk of meat as if it is an extended atom. One may not see the divisions in the meat, but just because the meat-tissues are interconnected and holding to one another does not mean divisions are not there everywhere. I believe philosophers often consider the divisions of an atomless spatiotemporal magnitude to exist as the division process,

25 Perrett writes, in the first lines of his article:

Consider the following familiar line of thought. Most of the objects in our immediate experience are composed of parts, and many of those parts are in turn composed of yet smaller parts, and so on, and on... But this process of decomposition cannot be endless: at some point we must come down to those fundamental impartite objects out of which all partite things are composed. These fundamental impartite objects are the metaphysical simples, the mereological atoms of the system $(2004,435)$. 
but we don't add more cuts to a preexisting divisionless (atomic) meat-slab, we merely cut meat that is already non-atomic and infinitely divided everywhere, if the meat is gunky.

Note Sider's claim that an atomless gunk item, A, is not describable by the mathematics of $\mathbf{R}$. But how can any extended atomless object A not be described with the mathematics of the real number line, $\mathbf{R}$ ? If $\mathbf{R}$ is made of points, how can't A be also? What other mathematical system, if not based in the $\mathbf{R}$ does describe gunk object A? No parts of $\mathbf{R}$ are not infinitely divided everywhere, but $\mathbf{R}$ is also a set of atom-points; and no parts of A are not infinitely divided everywhere, but $\mathrm{A}$ is not also a set of atom-points. What is it about A where it is not points but where $\mathbf{R}$ is? If $A$ is not made of points, as $\mathbf{R}$ is, what is it made up of? With A we are only dealing with its purported maximally and infinitely divided extension, and not with any points-of-being that compose A, wherein A is not isomorphic and analogous to $\mathrm{R}$ and its number-locations that are the elements of $\mathbf{R}$. But philosophers nevertheless use mathematics based on $\mathbf{R}$ (such as when using the non-integer rational number $1 / 3$, if $\mathrm{A}$ is divided as three parts) when describing the infinite divisions of $\mathrm{A}$ - so what do those mathematical operations based in $\mathbf{R}$ denote in $\mathrm{A}$ ? The answer would seem to be nothing at all. ${ }^{26}$

The problems for atomlessness become fatal when we analyze its marked feature: dividedness everywhere. Division (dividedness) is the feature of any atomless gunk object A that makes it different from an extended philosophical atom.

26 Ehrlich writes:

The real number system was dubbed the arithmetic continuum because it was held that this number system is completely adequate for the analytic representation of all types of continuous phenomena. In accordance with this view, the geometric continuum is assumed to be isomorphic with the arithmetic continuum, the axioms of geometry being so selected to ensure this would be the case. Since its inception, however, there has never been a time at which this now standard Cantor-Dedekind philosophy of the continuum has enjoyed the complete allegiance of philosophers, mathematicians, or scientists. One complaint that was, and to some extent still is, a stumbling block to the universal acceptance of the theory is the contention that the Cantor-Dedekind philosophy is committed to the reduction of the continuous to the discreet..., a program whose philosophical cogency, and even logical consistency, has been called into question since Zeno contended some 2500 years ago that a geometrical magnitude could neither be constituted from, nor decomposed to, points, on pain of contradiction $(2014,654-55)$.

Atomlessness would require discrete mathematics, based on integers rather than $\mathbf{R}$, seemingly introducing insurmountable problems, such as that discrete mathematics may forbid for essential imperative role of the attaching and touching of the discrete parts within any atomless mereological object (as discussed in the note below involving Chisholm's quote). 
Without division, A is not atomless, and the dividedness of A can only be such that $\mathrm{A}$ is divided maximally everywhere, lest atoms exist in A via any region of undividedness within A. In simpler words, there can be no extension within $A$ that is not maximally divided, lest A not be atomless gunk. But if A is maximally and infinitely divided everywhere, then what, exactly, is A's extension? There is no magnitude within $\mathrm{A}$ that is not described by this statement: if $\mathrm{A}$ is atomless then anywhere in A, no matter how small-scale, there will only be division, as the central feature of A. But amid such dividedness, does the stretched (magnitudinous) extension of a single surface consist as an extension? Amid such dividedness, what comprises any extendedness? If there is not division, then A is not atomlessness. If at any point whatsoever, if there is not division, and there is extension undivided, then within $\mathrm{A}$ is an extended partless atom. So extension (if it exists in gunky object A) is made up of divisions - division is a split, and extendedness is (somehow) composed of maximal splits. Indeed, any extension would mysteriously only be conceived as divisions "attached" to divisions, where no surface attaching to any other surface can be anything but the inter-attaching of maximal dividedness - overwhelmingly "divided surfaces" somehow attached to each other, by some means, amid infinite division-seams (and the surfaces seemingly could not attached via overlapping, lest they attach via a point ${ }^{27}$ ). But when we look at an empirical extension, probably that last thing we believe we empirically encounter is the totality of the object's magnitude being an infinity of splits and divisions.

27 At nowhere can there be undividedness, lest there be atoms, so does the divided-everywhere "extension" consist of attached segments, at every division-seam? But any surface that attached to any other would only consist of divisions everywhere \#1 (which is surface 1) attached to divisions everywhere \#2 (surface 2). I have not raised the daunting problem of how all the parts in an atomless object A can touch or attach, And in the context of the maximal dividedness of an atomless object $\mathrm{A}$, the problem becomes not one of how do surfaces touch or attach, but how do infinities of divisions and attach without there being any undivided (atomic) surfaces involved anywhere. On top of that, touching and attaching would be the feature that comprises the very extendedness and structure of any atomless gunk object, which makes matters worse for the philosopher of atomlessness, since attaching and touching of any objects, call them A and B, are enormously difficult to conceive, even before realizing that aforementioned mysteries for how gunks are really just "amalgamations of divisions”. Chisholm:

Consider two discrete physical bodies thought to be continuous with each other; the east side of body A, say, is continuous with the west side of body B... Either (i) the eastmost part of A is in the same place as is the westmost part of B or (ii) no part of A occupies the same place as does any part of $B$. In the case of (i), we would have two discrete things in the same place. But this is impossible. In the case of (ii), since A and B occupy different places, there is a place between the place where $A$ is and the place where $B$ is. But if there is a place between A and B, then A and B are not continuous" (Chisholm 1989, 84). 
But that is all that I could see wherever I look within A, almost as if atomlessness leads to concluding that atomless object $A$ is made up of nothingness. When I look in A, at any level, I can only be viewing rents and rifts, lest I see an atom, so where, then, is the extension? Is extension really defined as cuts and divisions everywhere? But how can cuts-and-only-cuts-everywhere at every area and aspect of the extension be what an extension is? Is not that more of the opposite of what we mean by extension, that there is something other than seams, rents, divisions, and cuts - namely the uninterrupted extension? If an extension is stretched and unbroken (that is, to contain at least something other than cuts and rifts), but utterly replete with infinite cuts and divisions everywhere, is not this to say that which is unbroken is divided everywhere, or, that which has union is composed of disunion, that which is without interruptions is composed only of interruptions, that which I experience as not divided or cracked is infinitely cracked and divided at every place, every area? When I look at the smooth extendedness of a piece of white paper, I typically don't think to myself while perceiving its extension that it is an infinite set of splits and divisions everywhere in the extension. Is not this all to say that extension = infinite dividedness, since everywhere there is maximal divideness?

The concept of extension breaks down when analyzing atomless gunk - when analyzing that it is infinitely divided everywhere lest it have extended atoms within it. And this is why the arithmetic of the $\mathbf{R}$ line would seem mathematical and correct, whereas the philosophy of atomless gunk is not: atomless gunk object A does not exist. Of everywhere and anywhere I look within any extension is only divisions (dividedness), so, where is any extension left over? Where does the extension remain, when anywhere all that can be seen is the maximally divided, not the ostensibly stretched-extended? Does infinite dividedness really lead to extension - or to only dividedness? For A, there are no dimensionless points, wherefore $A$ is only conceivable in terms of being a maximally divided extension: atomless extension is constituted of infinite dividedness, which appears to involve contradiction.

\section{There are no Extended Partless Atoms (Extended Simples)}

The reasoning of the previous section appears to reveal that atomlessness, in side-stepping the mathematics based on $\mathbf{R}$ number system (which is an atomic system), fails, since extension cannot consist only of dividedness (contradiction). If atomlessness fails, then we must consider atomism. All that is left to discuss is Democritean atomism, which are extensions that do not have proper parts, that are not divisible or divided (also referred to as extended simples in the literature). If there are no Democritean atoms, then premise 1 of the implantation argument cannot be avoided, since any magnitude would be composed 
of dimensionless atoms (which is impossible, wherein the extensions would be mindscreen simulation).

Let us call extended philosophical atoms Democritean atoms: partless philosophic atoms that have an irreducible spatial size. ${ }^{28}$ Just as atomlessness has involved a strong following through history in an attempt to avoid the dimensionless atomism of premise 1 of the implantation argument, so too has the philosophy of Democritean atomism, stemming from the ancient Greek atomists, and frequently adopted up to the present-day, many physicists and philosophers who hold a Democritean position. ${ }^{29}$ "It [has been]... believed [by some physicists] that a particle such as an electron [is] . . . a tiny solid ball with electric charge spread evenly throughout it". ${ }^{30}$ To avoid dimensionless atoms appears to largely be associated with why string theory and its later offshoots were invented. (The position that philosophic atoms are dimensionless and point-sized is also widely held. ${ }^{31}$ )

In this section I argue that Democritean atoms are only describable by a contradiction and thus do not exist, which would indicate that our only option for describing any reality of mind-independent spatiotemporal extensions reduces to dimensionless atomism (and therefore the implantation argument).

28 The phrase "Democritean atoms", is used by many; see, for example, Hoffman and Rosenkrantz (1997 13, 150-151), and Edgar (1979, 326). Nowadays philosophers often use the synonymous term, “extended simple” (Markosian 1998; McDaniel 2003, 2009; Simons 2004). Ehrlich (2014) involves an excellent account of this position.

29 For example, Markosian (1998), Simons (2004). This position was held by the ancient Greek Democritus, the Islamic atomist $\mathrm{Mu}^{\mathrm{c}}$ tazilites (Pines 1997, 110), and others. Hoffman and Rosenkranntz (1997, 13, 150-151) discuss this position, and it is widely held by many quantum gravity theorists.

30 Davies (1984), 107-108. Davies goes on to discuss the well-known problem with holding that an electron being atomic and having any extension whatsoever: "there is the vexing problem of what other forces could be present to counteract the electrical repulsion and so retain the electron in one piece" (107). Davies discusses yet further problems with the concept of the electron as a Democritean atom, which lead him to write: "physicists were compelled to abandon the idea of an electron as a solid ball. Instead, they came to regard it as a structureless point with no extension at all" (108), which, Davies explains, also led to further difficulties.

31 This position is held by Cohn and Varzi (2003), Hudson (2001), McDaniel (2003), Smith (1993), and many other philosophers, this is also a widely held position in relativity, the standard interpretation of quantum physics, and in quantum field theory. Watson, a physicist, writes: "Electrons are accepted as truly fundamental particles, indivisible and having no measurable size, so far as anybody knows”. (Watson 2004, 5). University of Michigan’s George Kane writes:

Why... do we [physicists] think that electrons and quarks are the true "Greek atoms"...? [I]nvestigators have tried by many means to determine whether electrons, quarks... and gluons show any evidence of structure, and they have not found any. These experiments 
It has become common in the philosophical literature to utter mild complaints (such as Steen 2011, 136) over how it is often assumed that if a philosophical atom is partless it is therefore point-sized (sizeless). Although intuitively obvious, the evidence for this pointiness of dimensionless philosophical atoms needs to be expressly shown. Often philosophers will resort to science to attempt to find this evidence, for either position: point-sized or extended philosophical atoms. ${ }^{32}$ But we have seen science posit that they have discovered partless philosophical atoms in the past, and then recant their position; that is how the scientist's "atom", which contains parts, such as electrons and quarks, and thus is not a partless philosophical atom, received its misnomer of a name ("atom"), that apparently we are now stuck with.

Democritean atomism involves the seemingly insurmountable problem of how to describe a partless, seamless, uncuttable, indivisible and undivided but nevertheless spatiotemporally extended philosophical atom. In simpler terms: how can a philosophical atom have a size but not any proper parts? ${ }^{33}$ In other words, if, for example, a Democritean atom is spherical, how can't it have a top and bottom half. This should be seen as absurdity, but understandably, there is tremendous desire for academics to try to explain how philosophical atoms can have extension, so to avoid the Zeno's metrical paradox ${ }^{34}$ (which leads to the mindscreen simulation).

probed perhaps 10,000 times further than it took to see structure in the past, but electrons and quarks continue to behave as point-like objects with no parts (Kane 2000, 21).

Notice that lurking in Kane's passage is the critical thinking fallacy called the appeal to ignorance: I have no evidence for X (yet), so there is no X - or in the context of Kane's passage: I have no evidence yet for the parts of the electron, so perhaps there are none.

32 For example, in discussing extended simples, Simons claims that a thesis of extended simples "is consonant with modern physics" (Simons 2004, 376).

33 I am holding to the seemingly self-evident view that a Democritean atom would have only one improper part, the entirety of the atom (this is what is meant by "partless atom").

34 In recent years it has become popular in the literature to propose that Zeno's metrical paradox was never what it seemed to be, only the illusion of a paradox, and various linguistic and metaphysical reasonings do-away with the supposed paradox. I deem these purported solutions to be more hopeful than evidential and logical. If these (I propose ad hoc and/or nonphilosophical caveats are abandoned I do not believed the result is so dreadful: the implantation argument is realized, reality is coherent, with an uncaused supernatural mystery as the direct cause of one's mindscreen consciousness. It is better to follow the logic rather than to invent hopeful philosophy that is devoid of inference. The most widely accepted of these supposed solutions 
Consider the spherical Democritean atom in the picture below, which has no proper parts, but has a size:

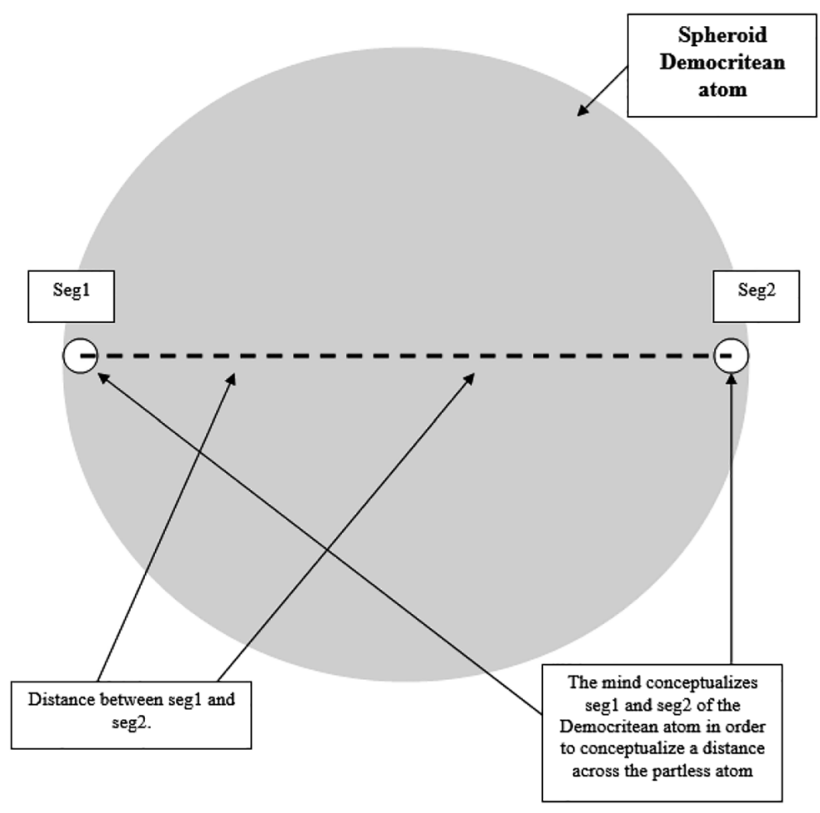

Call this Democritean atom D, and while it has no proper parts, the mind of the observer can conceptualize two segments, call them Seg1 and Seg2, "within" D, as shown. Seg1 and Seg2 are not proper parts, but are imaginary internal

is Grünbaum's. To expand on the points of an earlier footnote, the metaphysical conclusions of Adolf Grünbaum cannot be deemed to rescue one from the conclusions of this paper and from the premise 1 of the implantation argument. Edgar writes: "Grünbaum proposes to solve the Measure Paradox by arguing that extended space must be conceived as a relation among uncountably many unextended elements" $(1979,324)$ (Emphasis added). Edgar further voices the same puzzlement I have previously: "It is curious that Grünbaum views his account of physical space as an account for empirical science. The constituents of Grünbaum's 'space' are not empirical, and they seem to deny physical interpretation" $(1979,326)$. Metaphysical relations are not observable aspects of mind-independent empirically perceived reality. Grünbaum's account leads to the thesis that the solidity and hardness of the brick is ultimately caused by metaphysical “stuff”. In Grupp (2006), I showed that the metaphysical relation amongst the unextended points reduces to contradiction, showing that it is a troubled theoretical construct, not an aspect of the bedrock of mind-independent empirical externality. Philosophers, it seems, are therefore, it seems, too eager to explain-away Zeno's paradox of extension by merely using various sorts of metaphysical and invisible theoretical ideas. 
segments that the observer invents in the mind, and which do not exist (mindindependently). The observer can see the segments, but what the observer sees does not exist, since there is no way to distinguish Seg1 and/or Seg2 from each other or from D. The size (diameter) of $\mathrm{D}$ is shown by the dashed line, the distance across D - but how is diameter described in a situation where an entity has no proper parts? Distance is the noncoinciding of two entities that are nonidentical. There is distance when different entities do not coincide, where between them the mind realizes a gap or separation between the non-identical entities. But distance, as just defined, is specifically what a Democritean atom, a partless extended philosophical atom, cannot have. This is because to describe distance, from any here to any there, there must be two non-identical entities which are non-coinciding, but $\mathrm{D}$ does not have any nonidentical pieces, parts, internal entities, and so forth - Seg1 and Seg2 are imaginings of the mind, and there is only a oneness "inside" of D. Nothing is at a distance from itself. One cannot claim that there are any two distinct aspects of $\mathrm{D}$, lest one affirm the nonlogical concept that the distance from seg1 to seg2 is from "here" to "here" (where here $=$ here), since this D is only one improper part (partless), wherein any description of it has to describe all of it, the totality of D. And one cannot refer to any imagined piece of D, Seg1, as being here, and another imagined piece, Seg2, as there, in order to attempt to define a distance across a D, since those are imaginal (mind-dependent), and do not refer to anything possible or actual in an external spatiotemporal reality. There are no such non-identical pieces within, or to do with, D, so there is no way to understand D as having size or diametrical distance: $\mathrm{D}$ would be a sphere with no diameter (impossibility). The Democritean atom is something that absolutely requires a concept of size and distance in its definition and description, but where this sort of description is impossible. So, the Democritean atom is a contradiction and does not exist, ${ }^{35}$

35 Much of the discussion of Democritean atoms has been about so-called MaxCon simples (Markosian 1998), where the maximally continuous innards of the Democritean atom involve theorized seamlessness among continuum points. But are these continuum points not themselves atoms (dimensionless atoms)? I believe Simons has this same question, where in referring to Markosian (1998), he writes: "his own ... view, which he calls 'MaxCon', takes a simple to be a maximally continuous object... I do not accept this, not because such things might be large... but because it seems to me possible for a maximally continuously occupied region to contain more than one simple” (Simons 2004, 381). But let's say MaxCon is allowed to involve indistinguishability among all the innards of the atom, where the same dimensionless point exist at infinite locations within the atom's finite area. This would, it seems, could be a description of a seamless Democritean atom. But note, if this account of MaxCon is allowed, it still does not escape the objection just raised, where MaxCon would be a Democritean atom that involved a distance-less distance, there would not be any from here to there within MaxCon, which is 
where both atomlessness (atomless gunk) and Democritean atomism fail, and the implantation argument would be needed to make sense of moment-to-moment experience. Time, matter, and space, all would be susceptible to the arguments of this paper, and all would not involve mind independent coherent extensions: no extensions of time (duration), of matter (surface extension), or space (topological extension).

If an external physical reality is not composed of either Democritean atoms, or of atomlessness, then the only remaining option would be dimensionless atomism, which leads to the conclusion of the implantation argument: God exists. The ostensibly perceived hunks of matter and extensions can be divided up, such as when we break a brick into smaller and smaller pieces with a hammer, but if reality cannot be Democritean atoms or atomlessness, then at some point the dividing process collapses into absurdity. This would indicate that reality was never a mind-independent mereological complex in the first place, and that reality (mindscreen) must be of a different order altogether than that: a supernatural virtual cinema. There cannot be a consistent mereological world outside of the mind and represented internally; mind is a screen created by, and implanted by, a creator-God.

\section{Conclusion}

This article contains discovery of God (the Judeo-Christian God of infinite sacrificial love), and realization that any experiencing mind (mindscreen) can only be directly present with, and created, by God. We have found that the extensions of external reality cannot be mind-independent, and are a mindscreen. When one understands that their moment-to-moment experiencing is a mindscreen simulation, when the items of the reality the mindscreen are deemed as nonseparated, internal, virtual, and mentational, that mind-contents about externality are implanted not by externality, but rather by the creator-God, then one can understand reality accurately, and witness all "in Christ" omnipresently. Lastly, what I call simulation prayer is, I believe, the entire point of the discovery of God, and of the mindscreen simulation being created by the creator-God. Simulation prayer is when one understands that one's mind is a mere screen, where one is a mere simulation created by an all-loving creator-God, which, in my experience, leads to surprisingly, and occasionally shockingly powerful awareness of

required for their to be size and distance. So not even MaxCon seems to be able to escape the argument against Democritean atoms of this section. 
the omnipresent God - seemingly because by that accurate vision of the way of things, one can see what is real, where what is real is made known to awareness.

\section{References}

Bassett, P., and W. Greathouse. 1985. Exploring Christian Holiness, Volume 2: The Historical Development. Kansas City: Beacon Hill.

Baudrillard, J. 1994. Simulation and Simulacra. Ann Arbor: University of Michigan Press.

Bostrom, N. 2003. “Are You Living in a Computer Simulation.” The Philosophical Quarterly 211: $243-55$.

Bostrom, N. 2005. "The Simulation Argument: A Reply to Weatherson." The Philosophical Quarterly 55: 90-7.

Chalmers, D. 2005. “The Matrix as Metaphysics.” In Philosophers Explore the Matrix, edited by C. Grau. New York: Oxford University Press.

Chisholm, R. 1989. On Metaphysics. Minneapolis: University of Minnesota Press.

Cohn, A., and A. Varzi. 2003. "Mereotopological Connection." Journal of Philosophical Logic 32: 357-90.

Davies, P. 1984. Superforce: The Search for a Grand Unified Theory of Nature. New York: Touchstone.

Dreyfus, G. 1997. Recognizing Reality: Dharmakirti's Philosophy and its Tibetan Interpretations. Albany: State University of New York Press.

Edgar, W. 1979. “Locations.” Canadian Journal of Philosophy XI: 323-33.

Ehrlich, P. 2014. "An Essay in Honor of Adolf Grünbaum's Ninetieth Birthday: A Reexamination of Zeno's Paradox of Extension.” Philosophy of Science 81: 654-75.

Greene, B. 1999. The Elegant Universe. New York: W. W. Norton.

Grupp, J. 2006. “Grünbaum Did Not Solve Zeno's Measure Paradox.” The Proceedings of the Natural Philosophy Alliance 3: 44-9.

Hoffman, J., and G. Rosenkrantz. 1997. Substance: Its Nature and Existence. New York: Routledge.

Hudson, H. 2001. "Touching.” Philosophical Perspectives 15: 119-28.

Kane, G. 2000. Supersymmetry. Cambridge: Perseus Publishing.

Kawin, B. 1978. Mindscreen: Bergman, Godard, and First-Person Film. Princeton: Princeton University Press.

Lewis, D. 1991. Parts of Classes. Oxford: Basil Blackwell.

Markosian, N. 1998. "Simples." Australasian Journal of Philosophy 76: 213-26.

McDaniel, K. 2003. “Against Maxcon Simples.” Australasian Journal of Philosophy 81: 265-75.

McDaniel, K. 2009. “Extended Simples and Qualitative Heterogeneity.” The Philosophical Quarterly 59: 325-31.

McDonnell, K. 1998. "Theological Presuppositions in Our Preaching about Spirit.” Theological Studies 59: 219-35.

Mounce, H. 1999. Hume's Naturalism. New York: Routledge.

Perrett, R. W. 2004. “The Momentariness of Simples.” Philosophy 79: 435-45.

Pines, S. 1997. Studies in Islamic Atomism. Jerusalem: The Magnes Press.

Pyle, A. 1995. Atomism and its Critics. Bristol: Thoemmes Press.

Searle, J. 1977. The Mystery of Consciousness. New York: New York Review of Books.

Sider, T. 1993. "Van Inwagen and the Possibility of Gunk." Analysis 53: 285-9. 
Simons, P. 2004. "Extended Simples: A Third Way between Atoms and Gunk." The Monist 87: 371-84.

Smith, Q. 1993. “The Conceptualist Argument for God's Existence.” Faith and Philosophy 11: $38-49$.

Stang, C. 2012. Apophasis and Pseudonymity in Dionysius the Areopagite: No Longer I. Oxford: Oxford University Press.

Stang, C. 2016. Our Divine Double. Cambridge: Harvard University Press.

Steen, M. 2011. "More Problems for Maxcon: Contingent Particularity and Stuff-Thing Coincidence." Acta Analytica 23: 135-54.

Steinhart, E. 2010. "Theological Implications of the Simulation Argument." Disputandi 10: 23-37.

Vernes, J. R. 1999. The Existence of the External World: The Pascal-Hume Principle. Ottawa: University of Ottawa Press.

Watson, A. 2004. The Quantum Quark. New York: Cambridge University Press.

Webster, J. B. 1991. Eberhard Jüngel: An Introduction to His Theology. New York: Cambridge University Press.

Wittenkower, D. 2011. Philip K. Dick and Philosophy. Chicago: Open Court.

Zimmerman, D. 1996. "Could Extended Objects Be Made Out of Simple Parts? An Argument for 'Atomless Gunk'." Philosophy and Phenomenological Research 56:1-29. 